\title{
SOME PSYCHOLOGICAL ASPECTS OF PRIVACY
}

\author{
SIDNEY M. JoURARD*
}

Man's words and actions are intelligible to others only if the experience reflected therein is known or inferable. If an individual's behavior evokes puzzlement from another, the first may seek to give an account of the experiencing revealed by his action. But man, being free, may conceal his experiencing if he wishes, thus leaving the meaning of his acts a mystery for others to conjecture about. He may choose the time and place for disclosures of his experience, as well as the company before whom such disclosures are made. He may also elect to remain in solitude, so none can see or hear him. In extreme cases, a man may become mute and immobile, enacting a charade of invisibility or death. But so long as he remains alive, it is reasonable to assume that, even though he be thus unmoving and uncommunicative, he is yet disclosing some experience of the world, albeit in an undecipherable code. It will be assumed throughout this article that man always experiences the world in some mode; that he is always involved in some form of communication with other people; that he is always involved in some project or other; and that he is the embodiment of freedom.

Within this framework, which is adapted from the tradition of existential phenomenology, the state of privacy is related to the act of concealment. Privacy is an outcome of a person's wish to withhold from others certain knowledge as to his past and present experience and action and his intentions for the future. The wish for privacy expresses a desire to be an enigma to others or, more generally, a desire to control others' perceptions and beliefs vis-à-vis the self-concealing person. ${ }^{2} \mathrm{~A}$ man may seek to elude others' direct experience of his action, and he may seek to distort or misrepresent his experiencing to others in order that their view of him will not coincide with his direct view and knowledge of himself.

Why will a person allow himself to be seen or known? And why might he seek to conceal his being or to encourage others to form concepts and beliefs about his being that he knows are not veridical? What consequences follow from chronic selfconcealment, from authentic self-disclosure, from compulsory visibility? Under what conditions will a person reveal or conceal his being-for-himself, i.e., his experience, and before whom will his intended being-for-others coincide with his being-for-

- B.A. 1947, M.A., 1948, University of Toronto; Ph.D. 1953, University of Buffalo. Department of Psychology, University of Florida. Author, The Transparent Self (I964), Personal Adjustasent (1958; 2d ed. 1963).

2 See, e.g., Jean Paul Sartre, Being and Normingness (i956); Martin Heidegger, Being and Tinie (1962); Ronald D. Laing, The Divided Self (1960).

3 See Erving Goffman, The Presentation of Self in Everydar Life (1959), for an extended discussion of the techniques people commonly employ to influence the way they are seen by others. These techniques have not changed much since Machiavelli's time. 
himself? One may hope that the rough answers to these questions attempted below will be deemed relevant and useful in appraising the value of privacy in certain of its legal contexts.

\section{I}

\section{The INdividual and Society}

\section{A. The Pressures to Conform}

An adult person lives his life in relation to various social systems. He has status and fulfills roles within these systems. He is taught appropriate ways to behave, depending upon his age, sex, family position, occupation, and social class. If he does not conform to extant role-definitions, sanctions are directed against him. If his action violates codified laws, he may be imprisoned. If his behavior runs counter to prevailing codes of etiquette and morality, he may be ostracized or treated as persona non grata in informal social groupings. A person comes to fear these sanctions, the more so because he internalizes the expectation of them as he acquires his conscience. And so the fear of retribution for deviant action is reinforced by the possibility of guilt for violation of one's personal code.

A relatively recent kind of sanction applied against actions and utterances that are unacceptable, or not immediately intelligible to others, is the process of denigrating the actor or utterer by calling him "mentally ill." If a person cannot or will not learn expected roles, or continue to perform them in the approved way, he may be regarded by others not as bad or immoral but as "mad," a victim of some "mental disease." If he is so designated, his action is seen as an expression of unintelligible madness. The person is transmuted into a patient, and his behavior is construed as impersonal, dehumanized process and not as intentional action. When this happens, the person runs the risk of being deprived of his physical liberty. He can be hospitalized, so to remain until appropriate inspectors-usually psychiatrists-deem him cured. Prior to the pronouncement that he is cured or improved, the patient is subject to electric shocks, injections of insulin, administration of tranquilizing drugs, and conversations with a professional person (psychiatrist, psychologist, social worker, minister, or nurse), alone or in company with other patients. This last form of treatment is designated psychotherapy, as if the person's mind were being treated for a pathological mental infection.

Since every man is faced with the prospect of punishment or invalidation (transmutation from person to patient) for visible deviation from patterned role-behavior, he has a vested interest in how he appears before others. If he can seem to be lawabiding and in conformity with manners and morals that prevail in his social milieu, he will be spared society's sanctions; indeed, he may enjoy considerable free-

\footnotetext{
${ }^{3}$ One psychiatrist has pointed out that mental illness-or the designation of deviant behavior as a sickness-is a "myth" or a metaphor that has outlived its usefulness. See Tromas S. Szasz, Trie MYtri or MENTAL ILLNESS ( $196 \mathrm{r}$ ).
} 
dom to pursue projects that have value and meaning to him, such as the pursuit of wealth, or power, or creative achievement. And he may enjoy high status for success in any of these projects.

\section{B. Conformity and Health}

But chronic conformity with social roles will not yield only social approbation; physical sickness and "mental disease" (the refusal or inability to continue to fulfill roles in the expected ways) are also outcomes of role-conformity. Enactment of any social role appropriate to one's sex, age, or occupation calls upon one to suppress inappropriate action and to repress inappropriate experience. These praxes culminate in physical sickness or "role-check-outs" (mental illness). The morbidity rates in any society are thus an index of what extant role-definitions "cost" those who conform to them too closely and the society in general. Those who remain chronically well, though apparently role-abiding, have found arenas for safe, guilt-free expression of stifled experience.

If a person practices role-conformity faithfully and long enough, he will lose the capacity to recognize as his own those experiences-of impulses and feelings-that are incongruent with his desired role. He wishes to appear as a certain kind of person, not only to others but also to himself. If he wishes to appear to himself as a person without certain feelings and strivings, he will conceal all such experiences from himself. Freud used the term "repression" to designate the process of concealing experience from one's reflective self-awareness, and repression has long since been confirmed as a factor in those resignations from family or occupational roles that we have termed "mental illness." What is less generally recognized is that such repression, culminating in self-alienation, is also a factor in physical disease, whether caused by germs and viruses or by chronic stress. ${ }^{4}$

When a person continues to live his life in ways inimical to the needs of his physical organism, signals are emitted to the person (and to an observer who is perceptive or knowledgeable) that "all is not well" with the organism. If these signals are not acknowledged and acted upon in some ameliorative way, the person may experience pain, depression, anxiety, hopelessness, or vague malaise and not know why. The direct reason for these effects is to be found in the way the person so afflicted has been living his life. But if that way of life has been socially or morally exemplary, the person may be puzzled as to why he is not happy. A physician, unless he has been enlightened as to this source of disease, may anesthetize the distress signals with various medications, thus insuring that the person will continue with the very way of life that has been dispiriting him. Ultimately, if that way is indeed stressing and is truly lacking in opportunities for satisfaction and meaning, then

\footnotetext{
"The present writer has examined evidence which bears upon the dispiriting and illness-fostering effects of excessive conformity and repression. See Sidney M. Jourard, The Transparent Self esp. 79-ilo, I4I52 (1964).
} 
physical resistance will diminish, and infectious illness will arise. This may be treated with antibiotics only to recur. Or if organ systems are placed under stress by the procrustean roles the person has been enacting among others, these systems may break down. The person will suffer, apparently suddenly, a heart attack or a serious impairment of his digestive system.

Certain forms of concealment are thus deleterious to one's capacity to live life enjoyably and in good physical health. The quest for privacy in such cases has exceeded all bounds; the person has concealed his being not only from others but from himself. The outcome is that the man who has been husband, father, son, brother, and professional man is no longer able to fill those slots in the social roster of roles. He enters a new career, that of the patient. He may stay in that role for the rest of his life. But the structure of society has been kept intact.

If a person finds his roles stifling, unsatisfying, and meaningless and speaks and acts out his discontent, he will meet the onslaught of sanctions mentioned earlier. If he conceals his distress and discontent and impersonates a contented, conforming citizen, he may have a "breakdown" or become a socially invalidated mental patient. Is there no third option?

\section{The Therapeutic and Socially Necessary Functions of Privacy}

The experience of psychotherapists and of students of personality growth has shown that people maintain themselves in physical health and in psychological and spiritual well-being when they have a "private place," some locus that is inviolable by others except at the person's express invitation. This "private place" may be a physical location, such as a room, a cabin, a "pad," or a monastic cell. It may be a place for solitude, or it may be an ambience peopled by individuals who share the values and ideals held by the person in question. There, he can do or be as he likes and feels. He can utter, express, and act in ways that disclose his being-for-himself, and he does not need to fear external sanctions. Nor does he feel guilt for the discrepancy between the way he appears in public and the way he is in private. So long as his action is in conformity with the reasonable law of the land, the only limit upon his action and expression is the rights and wishes of others who may be present and his concern for his own physical well-being.

As society becomes more fully urbanized and institutionalized there are fewer and fewer such private places where a person can simply be rather than be respectable. It appears that it is only the intoxicated or the crazy ones living in locked wards who can be without fear of unforgiving criticism: "They act that way because they are drunk, or mad." But with the shrinkage of free space where a person can be "off-

\footnotetext{
'The "privacy" of mental patients is perhaps too well guarded; the conforming public is spared the sight of its socialization failures, who are kept in cold storage, and remains ignorant of the way mental hospital patients live their daily lives. Perhaps if there were less privacy associated with these hospitalsif more novels like KEN KESEY, ONE FLEW OVER THE Cuckoo's NEST (1962) were published-new ways for society to treat its failures would be invented.
} 
stage," the frequency of physical breakdown and withdrawal from social roles (mental illness) may be expected to increase. Or, as often happens, an entire nation can sustain its present mode of social organization only if all pent-up tension is transmuted into aggression directed to an external enemy, in organized warfare. More than one society has avoided collapse or revolution by virtue of a well timed war.

A society that would endure must draw a sharp distinction between public and private, if for no other reason than to make it a fit society within which people will gladly live-not just for material benefits but for the rich experience of existence that participation in the society affords.

\section{II}

\section{The Psychological Function of Self-Disclosure and Concealment}

Research in the activity of self-disclosure and my clinical experience as a psychotherapist have provided the empirical basis for the preceding remarks. It is appropriate at this point to look more directly at the phenomenon of self-disclosure in order to discern its relevance for a discussion of privacy.

Although some personality and cultural differences have been found to account for variance in self-disclosure, the most powerful determiner thus far discovered is the identity of the person to whom one might disclose himself and the nature and purpose of the relationship between the two people. ${ }^{b}$ More specifically, it has been found that disclosure of one's experience is most likely when the other person is perceived as a trustworthy person of good will and/or as one who is willing to disclose his experience in the same depth and breadth. In the former instance, the unilateral discloser expects he will benefit in some way if he permits the other person to know him as he is. This is the case in the relationship between patient and psychotherapist. Typically, the latter discloses himself to his patient little, if at all, whereas the patient makes his being "transparent," hoping that, by so doing, he will enable the therapist to help him overcome impasses in his existence.

But in ordinary social relationships, disclosure appears to be a reciprocal phenomenon. Each participant in dialogue will disclose his thoughts, feelings, actions, and so forth, to the other, and will be disclosed to in relevant response. This reciprocity of disclosure has been designated the "dyadic effect," and it can be stated as a proposition that "disclosure begets disclosure." Indeed, it has been found, in so-called "training groups," and in group therapy, that if the social context is created for risk-free disclosure people will gradually drop their facades and present themselves to their fellows in the ways they experience themselves. And considerable growth in self-understanding and understanding of others is regularly reported as a consequence of such assemblies. But the condition for such openness is the guarantee that whatever is presented to the other or others is disclosed in privacy; that is,

\footnotetext{
- Cf. Jourard, op. cit. supra note 4 , at $176-87$.
} 
the participants must feel assured that their disclosures will not be transmitted to others who are not present, that their social image-their being-for-others (outside the therapy group or the therapist's office)-will remain as it was until the person chooses to disclose more of his being in his usual roles.

It appears that privacy is essential for that disclosure which illumines a man's beingfor-himself, changes his being-for-others, and potentiates desirable growth of his personality. Since such healing encounters redound, ultimately, to the benefit of society at large, it is obvious that their privacy should be guaranteed. Hence, personal counselors and psychotherapists should enjoy legally guaranteed "privileged communication" so that they might be safely trusted by those who need to disclose themselves for the sake of their health.7 And society might well provide "checkout" places-private places less opprobrious than mental hospitals-where people can go to practice voluntary, limited disclosure, to engage in meditation or cathartic release, and to divest themselves temporarily of their usual roles in order ultimately to re-enter them refreshed and possibly with creative, socially integrative innovations in the way they fulfill them.

\section{III}

\section{Disclosure Inhibited and Privacy Denied}

\section{A. The Social Risk of Private Places}

Those responsible for ruling and leading a society, whether self-appointed or elected, have a vested interest in knowing what people are thinking, feeling, and doing. Their vested interest stems from the fact that it is only with such disclosure that the rulers can locate and deal with unorthodox ways of thinking and living. Even in a democracy, the various agents of socialization function as representatives of the ideology of the ruling classes, and they may spy upon people, reporting to the authorities what they have seen. The authorities then can take the necessary corrective or punitive steps to insure that present order will be maintained. Thus, parents, schoolteachers, ministers, and law-enforcement officers, and even public opinion in general, train people to behave in the ways they should (to keep the status quo), and they impose sanctions upon people who deviate from expected and approved conduct. This is obvious. What is less obvious is that the so-called healers in society--the psychiatrists and psychotherapists-often function in the same commissar-like fashion.

When other agents of socialization have not succeeded in shaping a person to the prescribed roles, the psychotherapists bring their influencing efforts and skill to bear upon the recalcitrant ones and train them to social acceptability using the promise of relief from suffering and the implied threat of deprivation of liberty as the incentives

\footnotetext{
(rg66).

${ }^{7}$ See generally Razph Szovenko, Psychotherapy, Confidentiality, and Privileged Comimunication
} 
for such training. But there may also be healers who could be seen as subversive. Each time one man reveals himself in privacy to another, a secret society springs into being. If the healer sees himself in the role of teacher or guru rather than as a further agent of socialization, he will aim at helping the sufferer gain a perspective on the social determiners in his existence and how he might transcend them. Just as drugs, like lysergic acid or marijuana, have a kind of releasing effect upon the consciousness of the user, so teachers and gurus have a "psychedelic" (mind-manifesting) effect upon those who consult with them. True consciousness-expansion (education) yields a transcultural perspective from which to view one's usual roles and the society within which one enacts them. The person liberated by a teacher from unquestioned compliance with roles and unquestioned pursuit of social values may be seen by others as a rebel or a revolutionary. As he reveals his expanded consciousness to others, he runs the risk of being seen as a threat to the status quo, whether in his family or in society at large. Thus, authoritarian governments cannot permit psychotherapeutic healers or teachers to pursue their work apart from the scrutiny of commissars and informers. Yet it is doubtful if true wholeness and full flowering of individuality is possible without the opportunity for true consciousness-expansion, in privacy or at least in safe company.

\section{B. Institutional Life}

Hospitals, prisons, military barracks, and live-in schools of all kinds deprive their inhabitants of privacy. This is part of the policy of those delegated to run such establishments, because in nonprivacy there is maximum opportunity to control behavior, to produce conformity to assigned roles. But where there is no privacy, there is little or no individuality. It is in such public places that Sartre's remark that "Hell is other people" takes on the most meaning. Authoritarian personalities, which are lost without external sources of control and guidance, seek out institutions that deprive them of privacy, because with privacy comes the awakening of freedom and its attendant responsibilities to direct one's own life. But for sentient, growing persons institutional life is hellish.

The whole process of a person's becoming a unit in an institution is one of divesting himself of his private existence. He no longer has a being-for-himself that has meaning or value to the institutional leaders. His thoughts, feelings, wishes, and beliefs are of interest to no one, unless they depart from the approved ideology. He has a being-for-the-institution; he is a "warm body," a source of behavior that may be of use and that must be no trouble to the institution. Beyond this, his being has no value. In its extreme case, institutional existence is manifested by the totalitarian state, or by life in society as Orwell envisioned it for 1984,9 where Big Brother could find out what people were doing anywhere simply by flipping a switch.

\footnotetext{
- Jean Paul Sartre, No Exit 47 (Vantage Books, 1947).

- George Orweli, I984 (1949).
} 
In totalitarian states of the recent past, people whose time could not be accounted for (who had a life concealed from others) were likely to be suspected of treasonable activities, imprisoned, and even killed.

In present-day America, architecture and living arrangements are such as to make it extremely difficult for people to find inviolate privacy either for solitude or for unobserved time spent in the company of another person. ${ }^{10}$ Houses seldom have soundproof rooms; indeed, they are often built on the open plan, so that inhabitants are seldom out of sight or earshot of one another. Lovers seldom have a place to be by themselves, unless it is found off somewhere in an automobile or by illicitly checking into a hotel or motel. Avoiding observation by others by whom one does not wish to be seen can become a desperate, futile, and costly quest in contemporary society. This state of affairs can make a prison or a dormitory out of one's daily living arrangement, producing the feeling that one has been condemned to his usual roles. This experience is most inimical to personal growth, the maintenance of physical and psychological health, and orderly nonviolent changes in the social structure.

\section{C. "Hell is Other People"}

Sartre's statement holds a psychological as well as an artistic truth. One view of "hell" is changelessness. The person who cannot grow, who experiences his own being and the being of the world as "frozen" in its present status, is in a kind of "hell." Other people can chain one to one's present ontological status by their very modes of relating. A parent, spouse, friend, or authority-figure can exert a pressure to keep one behaving, and even experiencing, in ritualistic modes. Freedom from the experienced impact of others' physical or psychological presence is the first step in the fulfillment of the freedom to grow. Artists, writers, scientists, and performers who aim at endless actualization of their possibilities attest to the need for solitude. They need it for meditation, rehearsal, and undisturbed pursuit of their ideas. One usually needs to leave other people behind in order to give up the way one has behaved in their presence. Being with people entails both a pledge to appear before the others as one has in the past (to practice the ways with which they are familiar and with which they can cope without strain to themselves) and pressure from the others to remain as one has been. "Going away" can be, and usually is, the first step in psychological growth.

One need not be in solitude to redefine one's being-for-oneself. One can go to a new place, where one's roles have not as yet been congealed in the minds of others. Privacy can be found among crowds of strangers. The problem faced by a person who has less mobility is how to change the concept that others have of him into a new one that encompasses his new phases of growth. Other people-close relatives

\footnotetext{
${ }^{10}$ See Sergius I. Chermayeff \& Christopher Alexander, Community and Privacy: Toward a New ARCHITECTURE OF HUMANisM (I963).
} 
and friends especially-tend to invalidate new ways of being that are disclosed by someone whom they have long known. They invalidate the growing person because they are threatened by his new incarnations. This is one of the reasons why alcoholics and drug addicts who have been cured (in a new place) frequently relapse when they go home. Others' expectations of them often prove more powerful than their redefined being-for-themselves.

\section{IV}

\section{Opting Out: The "Beatniks"}

When young people of the middle classes find that their elders embody roles and ways of life that seem meaningless, they may "opt out" and commence the "beat" way of life. This entails abandoning "respectable" dress and grooming, avoiding upwardly mobile training or work, and seeking the company of kindred souls. The "beatniks," who may be found in most large cities, spend their time in one another's company, listening to music, smoking marijuana, ingesting various psychedelic drugs, engaging in casual love affairs. In short, they have parted from their bourgeois pasts, and they envision no future that differs from their sensuous present. They seek a kind of privacy-an apartness from the "squares" and the law-enforcement officers, whom they see as defending the "squares"-in order to live their lives in the ways they find meaningful. This kind of opting out neither benefits nor harms society at large, except indirectly. The beatniks with whom I have been acquainted would, without doubt, have broken down physically or psychologically if they had remained in the roles for which socialization was preparing them. This would have resulted in perhaps more cost to society than the beat colonies presently impose. Of course, the larger cost is represented by the loss to society of talents for productive work that are not being cultivated by the beatniks; if they work at all, it is usually at transient, unskilled labor-just long enough to earn a little "bread" (money) to sustain them for the next stint of time.

I have been fortunate enough to gain the confidence of numerous such beat and off-beat characters. Many of them appear to live lives more in keeping with known requisites of physical and mental health than do their more respectable peers. They have lived their lives in privacy, away from the gaze of their parents, the police, those committed to suburban-bourgeois styles of living, and university administrators. They manage, through a highly developed sensitivity, to know when a "square" is within sight or earshot, at which point they "play it cool" and impersonate current models of role-conformity. But when they are in private, they behave with each other in spontaneous, joyous, exploratory, and growth-seeking ways. And they are not, as a rule, socially irresponsible, though some who are less educated may be. They take a keen interest in public affairs, domestic and foreign policy, and in standards of justice. But they also seek truth, beauty, and happiness in areas where 
they are most likely to be found, namely in honest interpersonal relationships, in nature, and so forth. Official efforts to root out these pockets of experimental living will, if successful, slow down existential exploration, the necessity for which is becoming increasingly apparent.

\section{PossibLe Solutions}

\section{A. Individual Stratagem and Check-Out Places}

Without the availability of private places, people suffer individually, and society suffers collectively. As a psychotherapist, I have frequently been called upon to help persons find more viable ways to live than those that have culminated in a breakdown. This quest for more viable ways has included advising a person to create or to find for himself a place where he can get away, to meditate, to experiment "offstage" with different ways to be, or simply to live his daily life without the pressures from his previous associates being present to bind him to his pathogenic life style. Another, and paradoxical, kind of solution has been to recommend the use of cunning and to instruct patients in the stratagems that may be employed. The paradox in this kind of advice appears because the patients fell ill through semblance and because part of the usual therapy would consist in helping the patient to confront the truth of his own being. Prior to his breakdown, the patient was playing a part before others, but believed that this was his real being. Following therapy, the patient would have learned to distinguish between his being-for-himself and his being-for-others and would have gained the freedom to discriminate between those situations where it is appropriate to disclose himself fully and those where it is more fitting and safe to play a part-but he would be always aware that he was "playing." Patients for whom this solution has worked were people who could find some ambience where they would not need to play roles but could be themselves.

From the standpoint of public mental health, I believe a real contribution could be made if the public health officials created, in every town, a socially acceptable check-out place to which people could go whenever they found their daily existence dispiriting. If existing mental hospitals could be demolished, and replaced by simple, attractive, modern equivalents of monasteries or by places for new, liberating experiences, then the need for the more violent or debilitating forms of psychiatric treatment would vanish.

\section{B. Education for Private Life}

In my opinion, our "educational" institutions are misnamed. The schools, from kindergarten through university, might better be called training institutions for promoting conformity in ideology and social behavior, for that is their most obvious yield. True education, by contrast, aims at awakening, illuminating, and expanding 
consciousness; at eliciting new possibilities of thinking, feeling, and acting; at exploring new realms of value; at providing standards of truth, beauty, and justice that afford a basis in consciousness for criticizing and modifying existing ways. People who emerge, thus educated, from our institutions of learning are rare. As less and less time becomes necessary to make a living and to produce material goods and services (as the result of technological advances and growing automation of training and productive enterprises), people will face the problem of "What shall I do with myself-and with other people-besides work, play stereotyped games, and watch TV?" Trained people (who are not educated) are terrified by empty time. Their private lives, lived with family, friends, and neighbors in off-work hours, will become an increasing burden and threat to their sanity and physical health. If exploration and inventiveness in ways to live, play, and interact with others is not permittedor, if permitted, is not conceivable or tolerable to rigidly trained people or is deemed sinful and illegal by the uneducated but trained populace-we can expect increasing rates of suicide, alcoholism and drug addiction, and psychological, spiritual, and physical breakdown.

The implication here is that schools and universities must aim at educating more people and at modifying general attitudes toward exploring ways to live. The trend at present is away from education, as schools and colleges tool up for more "programmed learning" to mass-produce more people who resemble bachelors of arts. If the general population came to believe (through authentic education and social example) that private life is free, that its privacy is to be respected, and that variety, not uniformity, in ways to live is a value, then the expected catastrophes following automation may be averted. Doubtless many antiquated laws-such as those dealing with the regulation of sexuality or with the use of non-narcotic psychedelic drugsmay have to be modified as a token of a new society's respect for the privacy of private life. Doubtless, too, those current aspects of family life that militate against the quest for viable and health-yielding ways to live in private will have to be changed. It is true that monogamous family structure (or some form of family structure) is necessary to protect and train the young. But our present ways of living family life appear to have been evolved more for their compatibility with modes of production than for their suitability as a social matrix that fosters growth of new ways to be by oneself or with others. A family-structure and style of life (including timing of meals, sleep, and so forth) that meshed with an agricultural, feudal, or industrial economy of scarcity cannot be expected to mesh as well with the developing affluent, automated society.

At the present time, those who live exploratory private lives that would be severely punished by law or public opinion may be the truest pioneers on the most relevant "New Frontier"- the frontier of new ways for man to live and be. When laws and customs change, these explorers-in-private may then reveal more publicly the ways in which they have been able to live their lives meaningfully, thus blazing new 
existential paths for the less imaginative to follow. But without legally guaranteed protection of private life, such experimentation in ways to live and to enrich the experience of leisure life are not likely to be forthcoming.

In short, privacy is experienced as "room to grow in," as freedom from interference, and as freedom to explore, to pursue experimental projects in science, art, work, play, and living. In the name of the status quo and other, even more attractive goals, privacy may be eroded. But without privacy and its concomitant, freedom, the cost to be paid for the ends achieved-in terms of lost health, weak commitment to the society, and social stagnation-may be too great. 